\title{
Prostanoid receptor EP1 expression in breast cancer
}

\author{
Mangesh A Thorat*, Akira Morimiya*, Sanjana Mehrotra, Raymond Konger and \\ Sunil S Badve \\ Department of Pathology and Laboratory Medicine, Indiana University School of Medicine, Indianapolis, \\ IN, USA
}

\begin{abstract}
Cyclooxygenase enzymes play an important role in carcinogenesis, and increased expression of cyclooxygenase enzymes has been reported in cancers arising at a number of different sites. Most, if not all of these actions are thought to be mediated by prostaglandin E2 (PGE2). The actions of PGE2 are mediated via four main prostanoid receptors, designated EP1, EP2, EP3 and EP4, based on their different pharmacological properties and secondary messenger pathways. Recently, expression of EP1 has been reported in rat mammary gland and the inhibition of this receptor has been documented to have chemopreventive effect in this animal model. EP1 has also been shown to decrease the incidence of colon cancer in mouse models. In this study, we analysed the expression of EP1 in normal and malignant breast tissues. Expression of EP1 was analysed in breast (benign and cancer) cell lines by reverse-transcriptase polymerase chain reaction and by western blot analyses. Expression was also analysed by immunohistochemistry in normal breast tissues and in 89 cases of breast cancer. Semiquantitative analysis of the staining was performed. The data were compared with and correlated with other prognostic factors like tumour size, tumour grade, lymph node status, oestrogen receptor, progesterone receptor (PR), HER2/neu and cyclooxygenase-2. EP1 expression was demonstrated in human breast cancer by immunohistochemistry. Expression of EP1 was seen both in the cytoplasm and/or in the nuclear membrane in majority of cases. Nuclear EP1 expression correlated with PR $(P=0.032)$ and inversely with node positivity $(P=0.025)$. However, EP1 expression did not correlate with expression of cyclooxygenase$2(P=0.059)$. Expression of EP1 is frequently seen in human breast cancers. Nuclear expression of EP1 correlates with good prognosis markers like node negative status and PR expression.
\end{abstract}

Modern Pathology (2008) 21, 15-21; doi:10.1038/modpathol.3800970; published online 28 September 2007

Keywords: breast cancer; EP1 receptor; cyclooxygenase; PGE2; prostanoid receptor; immunohistochemistry

Breast cancer is one of the most common malignancies in developed countries including USA, and the second leading cause of cancer-related deaths in women. ${ }^{1}$ As the incidence of breast cancer is increasing, several attempts at testing various preventive agents have been made (reviewed by Arun and Hortobagyi $\left.{ }^{2}\right)$. Nonsteroidal anti-inflammatory drugs (NSAIDs), which act through inhibition of cyclooxygenase enzyme (COX), are one such class of drugs that have been studied for their possible role in breast cancer prevention. Epidemiological studies

Correspondence: Dr SS Badve, Department of Surgical Pathology, Indiana University Hospital, 635 Barnhill Drive, MS-A128, Indianapolis, IN 46202, USA.

E-mail: sbadve@iupui.edu

This work has not been submitted elsewhere in part or completely. This was presented as an abstract at San Antonio Breast Cancer Symposium in year 2005.

* These authors contributed equally to this work.

Received 24 May 2007; revised 17 August 2007; accepted 5

September 2007; published online 28 September 2007 investigating the relationship between NSAID use and breast cancer have reported conflicting results; some studies ${ }^{3-5}$ show $30-40 \%$ reduction in breast cancer incidence with NSAID use, whereas others failed to confirm this relationship. ${ }^{6,7}$

NSAIDs work by inhibiting both constitutive and inducible cyclooxygenase enzymes (COX-1 and COX-2, respectively), both of which have been postulated to play a role in carcinogenesis. Elevated cyclooxygenase-2 (COX-2) expression is a marker of poor prognosis in human breast cancer and correlates with increased tumour size, negative oestrogen receptor (ER) status, HER-2 amplification and the presence of metastatic lesions. ${ }^{8}$ The importance of COX-2 is re-emphasised by the report that targeted expression of COX-2 in mouse mammary epithelium is sufficient to induce breast cancer. ${ }^{9}$ The selective COX-2 inhibitor, celecoxib, has been shown to have growth inhibitory effects on breast cancer cell lines and induces regression of DMBA-induced mammary tumours in rats. ${ }^{10}$ The potential for COX-2 inhibitors 
as chemopreventive agents has been demonstrated in several in vivo mouse models in which COX-2 inhibitors reduce the development of carcinogeninduced mammary tumours. ${ }^{11}$

The cyclooxygenase enzymes are involved in prostaglandin synthesis; prostaglandin E2 (PGE2) is an important mediator of tumorigenesis. ${ }^{12,13}$ PGE2 acts by binding to one of four separate receptors, $\mathrm{EP}_{1}$ through $\mathrm{EP}_{4}$, which are members of the rhodopsintype receptors coupled to hetero-trimeric GTPbinding proteins. ${ }^{14}$ Activation of $\mathrm{EP}_{1}$ and $\mathrm{EP}_{3}$ receptors leads to increased intracellular calcium and decreased cyclic AMP levels. $\mathrm{EP}_{2}$ and $\mathrm{EP}_{4}$ activation leads to opposing effects. ${ }^{15}$ Recent data suggest that antagonists (ONO-8711), which specifically block $\mathrm{EP}_{1}$ receptor, may also exhibit chemopreventive activity in several animal models of epithelial malignancy including breast cancer. ${ }^{16,17}$ A study by Zhao et al ${ }^{18}$ has also shown that the $\mathrm{EP}_{1}$ and $\mathrm{EP}_{2}$ receptors play an important role in the regulation of aromatase, which synthesises oestrogens locally in the breast.

$\mathrm{EP}_{1}$ expression in Sprague-Dawley rat mammary gland is restricted to tumours and not seen in normal tissues. ${ }^{16} \mathrm{EP}_{1}$ expression in human breast has not been studied before. We studied the expression of human $\mathrm{EP}_{1}$ receptors by immunohistochemistry in malignant breast lesions along with COX-2, oestrogen receptor (ER), progesterone receptor (PR) and HER-2/neu to correlate the pattern of expression with known prognostic factors in breast cancer. Expression of EP1 mRNA in human breast cell lines was confirmed by reverse-transcriptase polymerase chain reaction (RT-PCR).

\section{Materials and methods}

\section{Patient Characteristics}

Following an approval by the institutional review board, we examined representative sections of 10 normal breast tissues from patients undergoing reduction mammoplasty and 89 invasive breast cancer cases in which tumour was present in more than one block were selected (patient and tumour characteristics are detailed in Table 1). In addition to the invasive components, these tissue specimens also contained foci of normal breast lobules, fibrocystic disease and carcinoma in situ.

\section{Immunohistochemistry}

Following de-waxing and hydration, $4 \mu \mathrm{m}$ sections from archival paraffin-embedded tissue were treated with a combination of $75 \%$ glycerol and 25\% $1 \times$ Dako high-pH antigen-retrieval solution in a decloaking chamber (BioCare ${ }^{\circledR}$, Walnut Creek, CA, USA) with chamber settings of SP $1125^{\circ} \mathrm{C}$ for $5 \mathrm{~min}$, and SP2 $90^{\circ} \mathrm{C}$ for $10 \mathrm{~s}$. The slides were then cooled for $20 \mathrm{~min}$ at room temperature. Endogenous
Table 1 Patient and tumour characteristics

\begin{tabular}{lr}
\hline Parameter & Number \\
\hline Sex & \\
$\quad$ Female & 88 \\
Male & 1 \\
Age (years) & \\
$\quad<50$ & 31 \\
$\quad$ >50 & 58 \\
Type of tumour & \\
IDC & 78 \\
ILC & 11 \\
Histological grade & \\
I & 18 \\
II & 41 \\
III & 30 \\
Lymph node status & \\
Positive & 37 \\
Negative & 44 \\
ER status & \\
Positive & 53 \\
Negative & 36 \\
PR status & \\
Positive & 35 \\
Negative & 54 \\
\hline
\end{tabular}

IDC, invasive duct carcinoma; ILC, invasive lobular carcinoma.

peroxidase activity was blocked by Peroxo-block (Zymed, San Francisco, CA, USA) for $1 \mathrm{~min}$. The slides were then incubated with EP1 antibody (Cayman Chemical, MI, USA) for $1 \mathrm{~h}$ at room temperature. The sections were incubated with HRP polymer conjugate (Zymed) according to the manufacturer's instructions. The stain was visualised using $\mathrm{DAB}$ plus (DakoCytomation, Carpenteria, CA, USA) and haematoxylin QS (Vector Laboratories, Burlingame, CA, USA) counterstain. The specificity of EP1 staining was assessed by peptide inhibition assay using peptide supplied by the manufacturer of the antibody (Cayman Chemical). Supernatant obtained after antibody-peptide interaction was used for negative controls (Figure 1a).

\section{Immunohistochemical staining for $E R, P R$ and HER-2/neu}

Immunohistochemical staining was performed on serial sections for ER (Clone SP1 NeoMarkers, Fremont, CA, USA) and PR (PR636 DakoCytomation) and Hercept Test $^{\circledR}$ using protocols recommended by the manufacturer (DakoCytomation).

\section{Immunohistochemical staining for $\mathrm{COX}-2$}

Immunohistochemical staining was performed on serial sections for COX-2 using monoclonal mouse anti-human COX-2 antibodies (1:50, clone CX229, Cayman Chemical, Ann Arbor, MI, USA) according to the manufacturer's instructions. 

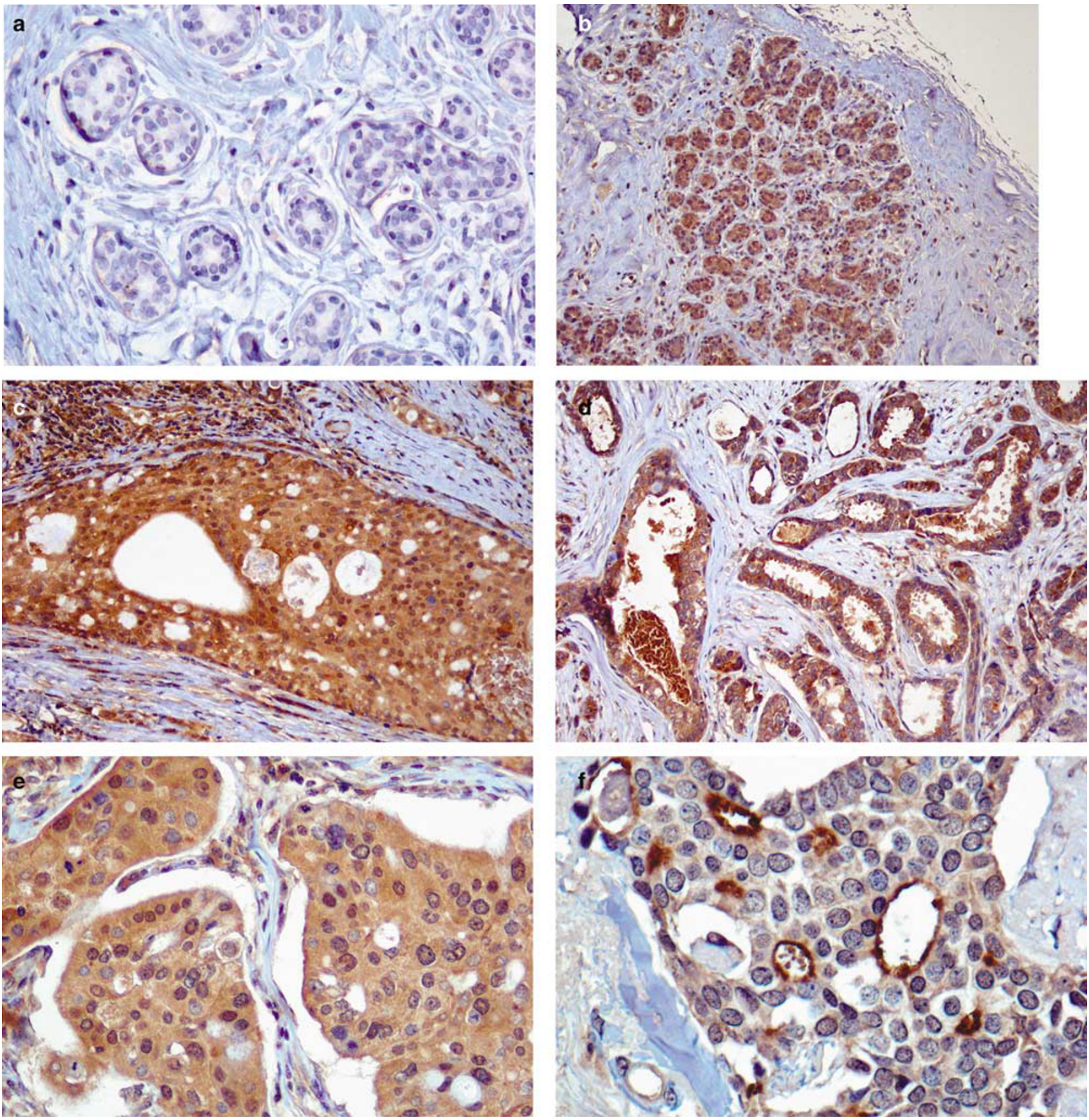

Figure 1 Expression of EP1 in normal breast and in breast cancer. (a) Negative control, (b) Normal lobule, (c) DCIS, (d) Invasive carcinoma, (e and $\mathbf{f}$ ) variable nuclear and cytoplasmic expression in breast cancers cases.

\section{Evaluation of immunohistochemical staining}

ER and PR status was assessed from stained immunohistochemistry sections using a $10 \%$ cutoff. HER-2/neu expression was scored as $0,1+$, $2+$, and $3+$ as recommended by the manufacturer (DakoCytomation).

For EP1, analysis of both nuclear and cytoplasmic expression was performed. The intensity of nuclear expression was assessed on a scale of $0-3$ for intensity such that 0 represented no staining and ' 1 ' weak intensity, ' 2 ' moderate intensity, and ' 3 ' strong intensity. Similarly, percentage of expression was analysed on a 0-10 scale such that 0 represented no staining and 10 represented staining of $100 \%$ of tumour cells. The two scores were then multiplied. Final scores of more than 6 were regarded as positive expression. For cytoplasmic EP1 expression, reactivity in more than $10 \%$ tumour cells was regarded as positive expression.

For COX-2, the percentage of cells with granular cytoplasmic staining was scored from 0 to $4(0=0 \%$ positive cells; $1=<10 \%$ positive cells; $2=10-50 \%$ positive cells; $3=50-80 \%$ positive cells; $4=>80 \%$ positive cells) and staining intensity was scored 
from 0 to 3 ( 0 negative; $1=$ weak, $2=$ moderate; $3=$ strong). The two scores were then multiplied. Final scores of more than 6 were regarded as positive expression. ${ }^{8,19}$ Expression of COX-2 in endothelial cells was also recorded.

\section{Cell Culture}

Cell lines were obtained from the American Type Culture Collection (Manassas, VA, USA). MCF-7 and MDA-MB-231 were cultured in DMEM/F12 medium (Invitrogen Corp., Carlsbad, CA, USA) supplemented with $10 \%$ foetal clone III (Hyclone, Logan, UT, USA). MDA-MB-468, SK-BR-3, Hs 578T and T-47D were grown in MEM alpha modified medium (Invitrogen Corp.) supplemented with 10\% standard foetal bovine serum (FBS) (Hyclone). ZR-75-1 and DU4475 were cultured in RPMI 1640 (Invitrogen Corp.) supplemented with $10 \%$ standard FBS (Hyclone), $4.5 \mathrm{~g}$ D-glucose (Sigma-Aldrich, St Louis, MO, USA), $10 \mathrm{mM}$ HEPES (Sigma-Aldrich) and $1 \mathrm{mM}$ sodium pyruvate (Cambrex Bio Science Inc., Rockland, ME, USA). MCF-10A was cultured in DMEM/F12 medium (Invitrogen Corp.) supplemented with $20 \mu \mathrm{g} / \mathrm{ml}$ epidermal growth factor (R\&D systems, Minneapolis, MN, USA), $10 \mu \mathrm{g} / \mathrm{ml}$ insulin (Sigma-Aldrich), $0.5 \mu \mathrm{g} / \mathrm{ml}$ hydrocortisone (SigmaAldrich) and $1 \mathrm{mM}$ sodium pyruvate (Cambrex Bio Science Inc.). All of the cell lines were supplemented with 1:1000 penicillin $(5 \mathrm{U} / \mathrm{ml})$ :streptomycin ( $5 \mu \mathrm{g} / \mathrm{ml}$ ) (Invitrogen Corp.).

\section{RNA Isolation and RT-PCR Analysis}

Total RNA was isolated from cells grown in $100 \mathrm{~mm}$ Petri dishes using TRIzol reagent (Invitrogen Corp.) and dissolved in RNA secure resuspension solution (Ambion Inc., Austin, TX, USA) according to the manufacturer's protocols. The isolated RNA was quantified by a spectrophotometric method. Quality of isolated RNA was assessed by the ratio of absorbance at 260 and $280 \mathrm{~nm}$. Integrity of the isolated RNA was then checked by determining the ratio of $28 \mathrm{~S}$ and $18 \mathrm{~S}$ after electrophoresis in a $1 \%$ agarose gel. In a $50 \mu \mathrm{l}$ reaction volume, $10 \mu \mathrm{g}$ of total RNA was treated with TURBO DNA-free (Ambion Inc.), as required by the protocol. First-strand cDNAs were synthesised from $9 \mu \mathrm{l}$ of TURBO DNase-treated RNA using the Thermoscript RT-PCR system (Invitrogen Corp.) with random hexamer primers at $50^{\circ} \mathrm{C}$ for $50 \mathrm{~min}$. PCR amplification was carried out using HotStarTaq master mix kit (Qiagen Inc., Valencia, CA, USA) with $0.2 \mu \mathrm{M}$ of each sense and antisense primer. For EP1, $1 \mu \mathrm{l}$ of this RT reaction was used. Also, to enhance PCR, $1 \mu \mathrm{l}$ of DMSO (Sigma-Aldrich) was included. Each reaction consisted of initial Taq polymerase activation at $95^{\circ} \mathrm{C}$ for $15 \mathrm{~min}$ and then 40 cycles of $94^{\circ} \mathrm{C}$ for $30 \mathrm{~s}, 56.0^{\circ} \mathrm{C}$ for $30 \mathrm{~s}, 72^{\circ} \mathrm{C}$ for $45 \mathrm{~s}$ and additional 2 min extension at $72^{\circ} \mathrm{C}$ after the last cycle in the Eppendorf MasterCycler (Eppendorf, Westbury, NY, USA). Expression of the 36B4 gene was used as a positive internal control for cDNAs. For 36B4, $0.5 \mu \mathrm{l}$ of the RT reaction was used. PCR cycle parameters were $95^{\circ} \mathrm{C}$ for $15 \mathrm{~min}$ and then 35 cycles of $94^{\circ} \mathrm{C}$ for $30 \mathrm{~s}, 54^{\circ} \mathrm{C}$ for $30 \mathrm{~s}, 72^{\circ} \mathrm{C}$ for $45 \mathrm{~s}$ and additional $2 \mathrm{~min}$ extension at $72^{\circ} \mathrm{C}$ after the last cycle.

PCR products were visualised under UV light after electrophoresis (Figure 2) through a $\%$ agarose gel containing $0.01 \mu \mathrm{g} / \mathrm{ml}$ ethidium bromide (Bio-Rad Laboratories). The size of PCR products was determined using a $50 \mathrm{bp}$ DNA ladder (Invitrogen Corp.). The primer sequences are listed in Table 2. EP1 primer set was obtained from Sigma-Genosys (The Woodlands, USA). 36B4 primer set was obtained from Integrated DNA technologies (Coralville, IA, USA).

\section{Statistical Analysis}

All analyses were performed using SPSS 14.0 software (SPSS Inc., Chicago, IL, USA). $\chi^{2}$ and Fisher Exact tests were applied for comparisons between two parameters, ' $P$ ' values of $<0.05$ were considered significant. Bivariate correlations and partial correlations with appropriate control variable were performed to determine Spearman's Rho values. All ' $P$ ' values are two-tailed unless specified otherwise.

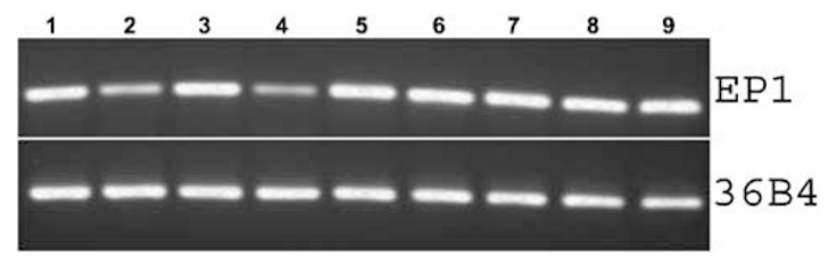

Figure 2 Qualitative RT-PCR showing expression of EP1 and 36B4 (RT control) in breast cancer cell lines. (1) MCF-10A, (2) MCF-7, (3) MDA-MB-231, (4) MDAMB-468, (5) SK-BR-3, (6) Hs 578T, (7) ZR-75-1, (8) T-47D and (9) DU4475.

Table 2 Oligonucleotide primer pairs for RT-PCR

\begin{tabular}{|c|c|c|c|c|}
\hline Gene & Primer sequence $5^{\prime}-3^{\prime}$ & Positions & Product size (bp) & Gene bank \\
\hline EP1 & ATC ATG GTG GTG TCG TGC AT & 1022 & 149 & NM_000955.2 \\
\hline (human) & TAC ACC CAA GGG TCC AGG AT & 1170 & & \\
\hline 36B4 & TGC AGC TGA TCA AGA CTG GAG ACA & $473-496$ & 178 & M17885 \\
\hline (human) & TCC AGG AAG CGA GAA TGC AGA GTT & $650-627$ & & \\
\hline
\end{tabular}




\section{Results}

The majority of breast tumours (88\%) were infiltrating ductal carcinomas, rest being infiltrating lobular carcinomas (Table 1). Median age at diagnosis was 54 years (range 28-85), and 31 (35\%) patients were less than 50 years old. Tumour size ranged from 0.2 to $13 \mathrm{~cm}$ (median size, $1.5 \mathrm{~cm}$ ). In 37 cases $(42 \%)$, axillary lymph nodes showed metastases. Thirty-six $(40 \%)$ and 35 (39\%) tumours expressed ER and PR, respectively, while $62(70 \%)$ tumours expressed either of the hormone receptors. HER-2/neu was found in 48 cases ( $54 \%$ ), possibly due to selection of larger tumours. None of the cases of lobular carcinoma showed HER-2/neu positivity.

\section{EP1 in the Normal Breast by Immunohistochemistry}

The expression of EP1 in the normal breast was restricted to the lobules (Figure 1b), and it was seen both in the cytoplasm and nuclei of epithelial and myoepithelial cells.

\section{EP1 in the Breast Cancer by Immunohistochemistry}

In cancers, the expression of EP1 was seen in some but not all tumours. Tumours that exhibited expression could show nuclear or cytoplasmic localisation of the staining of the neoplastic cells (Figure 1d-f). In addition to the tumour cells, expression was also seen in the cytoplasm of endothelial cells and rare scattered stromal cells. Stromal/endothelial cell staining was independent of tumour cell expression of EP1; being seen in both EP1-positive and -negative tumours. Cytoplasmic expression was seen in $70(79 \%)$ cases, while nuclear reactivity was noted in $36(40 \%)$ cases. In $24(27 \%)$ cases, both cytoplasmic and nuclear expression was noted.

\section{COX-2 in the Breast Cancer by Immunohistochemistry}

The expression of COX-2 in normal breast is seen in the form of diffuse cytoplasmic staining of breast lobules. In addition, the expression is seen in inflammatory cells and fibroblasts. The pattern of expression in neoplastic cells was similar to that of normal. COX-2 was strongly expressed in $53(60 \%)$ cases, weakly expressed in $17(19 \%)$ cases and expression was absent in $19(21 \%)$ cases.

\section{Correlations among Various Immunohistochemical Parameters}

ER expression correlated positively with PR expression $(P=0.022)$ and negatively with COX-2 $(P<0.0009)$. With worsening tumour grade, there was loss of ER and PR expression $(P<0.0009$ and $P=0.016$ respectively). PR expression correlated positively with nuclear EP1 expression $(P=0.032)$ and negatively (inverse correlation) with cytoplasmic EP1 expression $(P=0.016)$.

Cytoplasmic EP1 expression correlated negatively with PR $(P=0.016)$ and nuclear expression $(P=0.023)$. Nuclear expression of EP1 showed negative correlation with tumour grade $(0.034)$ and although nonsignificant $(P=0.059)$, with COX-2 expression. Fifty per cent $(9 / 18)$ of grade I tumours showed nuclear EP1 expression as compared to only $23.3 \%$ (7/30) grade III tumours. The most important correlation we observed was nuclear EP1 expression with nodal status; tumours with nuclear expression of EP1 had less likelihood of nodal metastasis $(P=0.025)$.

\section{EP1 mRNA Expression in Breast Cell Lines by RT-PCR}

All cell lines expressed EP1 mRNA, with a qualitative RT-PCR showing $149 \mathrm{bp}$ band with all breast cancer cell-line samples (Figure 2).

\section{Discussion}

This is the first study to analyse EP1 expression in human breast cancers using molecular and immunohistochemical methods. EP1 mRNA is detected in human breast cell lines by RT-PCR and is detected by immunohistochemistry in human breast cancer tissues as well. This suggests that EP1 may be a component of the COX-2-mediated carcinogenetic process in breast. However, EP1 is only one of four receptors for PGE2. Of the other receptors, EP-3 and EP-4 are high affinity receptors that are expressed more or less ubiquitously in all tissues examined (data not shown). EP-2, like EP1, is a low affinity receptor, which is thought to play important role in modulating the response of cells/tissues to PGE2 ${ }^{20}$ Analysis of EP2 receptor was also performed in the current study however this data is not presented due to more recent questions about specificity of the commercially available antibody.

Expression of EP1 is seen in cytoplasm of normal breast epithelium and additionally in the nucleus of cancer cells. This pattern of expression has been previously observed in the epidermis ${ }^{21}$ and similarly reported in crude rat skin subcellular membrane preparations by radioligand binding. ${ }^{22}$ This dual pattern of expression is similar to the pattern described for COX-1 and $-2 .^{23,24}$

In the skin, EP1 expression is believed to play a role in keratinisation. In normal skin, it is predominantly seen in the stratum granulosum, where it correlates with the presence of keratohyaline granules. Additionally, in squamous cell carcinomas (SCC) of the skin, cytoplasmic EP1 expression correlates with the degree of epidermal differentiation. ${ }^{25}$

In breast, we did not find a correlation of cytoplasmic EP1 with differentiation (tumour grade) or node negative status. On the other hand, nuclear EP1 expression correlated with absence of nodal 
metastases and differentiation (tumour grade). This suggests that EP1 has distinct functions depending upon its localisation. In the cytoplasm, where it is frequently colocalised with COX-2, it seems to lead to poor prognosis. On the other hand, nuclear localisation leads to the activation of differentiation pathways via as yet undescribed mechanisms.

In addition to direct effects in breast cancer cells, COX-2/PGE2 pathway is also incriminated in regulation of aromatase activity in stromal (myo)fibroblasts. ${ }^{18}$ This is believed to be predominantly via the EP1 receptor through protein kinase A (PKA) or protein kinase $\mathrm{C}$ (PKC) pathway. ${ }^{26}$ Although, correlation of nuclear expression of EP1 with expression of COX-2 was not statistically significant $(P=0.059)$, significant correlation of nuclear expression of EP1 with PR (indicator of active oestrogen/ER pathway) may be mediated through local oestrogen production by aromatase upregulation.

The exact role of nuclear and cytoplasmic receptors of PGE2 is poorly understood. One of the reasons for this is the presence of four distinct receptors with varying degrees of affinity and associated with different G-protein alpha specificities and second messenger pathways that are activated upon ligand binding. It is apparent from the results of the current study that nuclear and cytoplasmic expression, at least in the breast, is associated with distinct differences in function and ultimately in modulating behaviour of breast cancer cells. Such differential expression calls for further mechanistic studies to explore downstream pathways.

\section{Acknowledgement}

This study was supported by the NCI grant to ECOG (CA 37403) 'Supplement for Correlative studies related to ER-negative breast cancer-Prostaglandin E2 receptors in breast cancer' to SB. RK was supported by NIH K08 AR.

\section{Conflicts of interest}

All authors hereby declare that we have no conflicts of interest.

\section{References}

1 CDC. (cited 15 January 2007). Available from:http:// www.cdc.gov/cancer/breast/statistics/.

2 Arun B, Hortobagyi GN. Progress in breast cancer chemoprevention. Endocr Relat Cancer 2002;9:15-32.

3 Harris RE, Kasbari S, Farrar WB. Prospective study of nonsteroidal anti-inflammatory drugs and breast cancer. Oncol Rep 1999;6:71-73.

4 Leris C, Mokbel K. The prevention of breast cancer: an overview. Curr Med Res Opin 2001;16:252-257.

5 Nakatsugi S, Ohta T, Kawamori T, et al. Chemoprevention by nimesulide, a selective cyclooxygen- ase-2 inhibitor, of 2-amino-1-methyl-6-phenylimidazo[4,5-b]pyridine (PhIP)-induced mammary gland carcinogenesis in rats. Jpn J Cancer Res 2000;91: 886-892.

6 Egan KM, Stampfer MJ, Giovannucci E, et al. Prospective study of regular aspirin use and the risk of breast cancer. J Natl Cancer Inst 1996;88:988-993.

7 Paganini-Hill A, Chao A, Ross RK, et al. Aspirin use and chronic diseases: a cohort study of the elderly. BMJ 1989;299:1247-1250.

8 Ristimaki A, Sivula A, Lundin J, et al. Prognostic significance of elevated cyclooxygenase-2 expression in breast cancer. Cancer Res 2002;62:632-635.

9 Liu CH, Chang SH, Narko K, et al. Overexpression of cyclooxygenase-2 is sufficient to induce tumorigenesis in transgenic mice. J Biol Chem 2001;276: 18563-18569.

10 Alshafie GA, Abou-Issa HM, Seibert K, et al. Chemotherapeutic evaluation of Celecoxib, a cyclooxygenase2 inhibitor, in a rat mammary tumor model. Oncol Rep 2000;7:1377-1381.

11 Howe LR, Subbaramaiah K, Brown AM, et al. Cyclooxygenase-2: a target for the prevention and treatment of breast cancer. Endocr Relat Cancer 2001;8:97-114.

12 Yoshimatsu K, Altorki NK, Golijanin D, et al. Inducible prostaglandin E synthase is overexpressed in nonsmall cell lung cancer. Clin Cancer Res 2001;7: 2669-2674.

13 Yoshimatsu K, Golijanin D, Paty PB, et al. Inducible microsomal prostaglandin E synthase is overexpressed in colorectal adenomas and cancer. Clin Cancer Res 2001;7:3971-3976.

14 Breyer RM, Bagdassarian CK, Myers SA, et al. Prostanoid receptors: subtypes and signaling. Annu Rev Pharmacol Toxicol 2001;41:661-690.

15 Chell S, Kadi A, Williams AC, et al. Mediators of PGE2 synthesis and signalling downstream of COX-2 represent potential targets for the prevention/treatment of colorectal cancer. Biochim Biophys Acta 2006;1766: 104-119.

16 Kawamori T, Uchiya N, Nakatsugi S, et al. Chemopreventive effects of ONO-8711, a selective prostaglandin $\mathrm{E}$ receptor EP(1) antagonist, on breast cancer development. Carcinogenesis 2001;22:2001-2004.

17 Watanabe K, Kawamori T, Nakatsugi S, et al. Role of the prostaglandin E receptor subtype EP1 in colon carcinogenesis. Cancer Res 1999;59:5093-5096.

18 Zhao Y, Agarwal VR, Mendelson CR, et al. Estrogen biosynthesis proximal to a breast tumor is stimulated by PGE2 via cyclic AMP, leading to activation of promoter II of the CYP19 (aromatase) gene. Endocrinology 1996;137:5739-5742.

19 Denkert C, Winzer KJ, Muller BM, et al. Elevated expression of cyclooxygenase-2 is a negative prognostic factor for disease free survival and overall survival in patients with breast carcinoma. Cancer 2003;97: 2978-2987.

20 Breyer RM, Kennedy CR, Zhang Y, et al. Structurefunction analyses of eicosanoid receptors. Physiologic and therapeutic implications. Ann N Y Acad Sci 2000;905:221-231.

21 Konger RL, Billings SD, Thompson AB, et al. Immunolocalization of low-affinity prostaglandin E receptors, EP and EP, in adult human epidermis. J Invest Dermatol 2005;124:965-970.

22 Lord JT, Ziboh VA. Specific binding of prostaglandin E2 to membrane preparations from human skin: 
receptor modulation by UVB-irradiation and chemical agents. J Invest Dermatol 1979;73:373-377.

23 Morita I, Schindler M, Regier MK, et al. Different intracellular locations for prostaglandin endoperoxide H synthase-1 and -2. J Biol Chem 1995;270:10902-10908.

24 Otto JC, Smith WL. The orientation of prostaglandin endoperoxide synthases-1 and -2 in the endoplasmic reticulum. J Biol Chem 1994;269:19868-19875.
25 Lee JL, Kim A, Kopelovich L, et al. Differential expression of $\mathrm{E}$ prostanoid receptors in murine and human non-melanoma skin cancer. J Invest Dermatol 2005;125:818-825.

26 Zhao Y, Agarwal VR, Mendelson CR, et al. Transcriptional regulation of CYP19 gene (aromatase) expression in adipose stromal cells in primary culture. J Steroid Biochem Mol Biol 1997;61:203-210. 